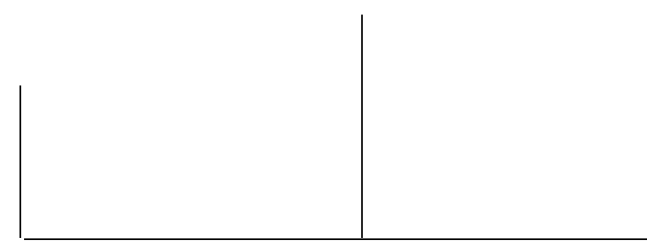

Rev. Latinoam. Psicopat. Fund., VIII, 4, 596-616

\title{
Sacrificio y paradojas de los Nombres del Padre
}

Marta Gerez Ambertín

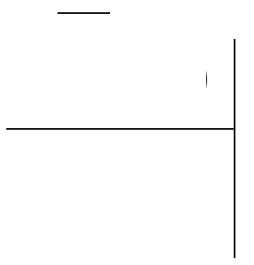

El sacrificio en la teoría psicoanalítica, y desde el corpus freudo-lacaniano, es una de las consecuencias de las paradojas del padre.

Precísase acudir al mito del sacrificio de Abraham para despejar las cuestiones de las paradojas de los Nombres del Padre y del fracaso de la metáfora paterna; y asimismo, destacar que no es posible reducir los Nombres del Padre a dicha metáfora. Siendo el sacrificio una respuesta a la falta del Otro y con lo que se pretende su captura, ese ofrecimiento intenta garantizar que el Otro existe ya sea por las vías del goce o por las del deseo.

Trazamos este ofrecimiento sacrificial en el mito de Abraham e Isaac y sus consecuencias en la clínica del deseo y el goce.

Palabras clave: Sacrificio, nombres del padre, objeto $a$, voz, goce y deseo del Otro 
... en el sacrificio de Abraham, lo que resulta sacrificado es efectivamente el padre, que no es otro que un carnero. Como en toda estirpe humana que se respete, su ascendencia mítica, es animal.

Lacan, 1/6/72

\section{El sacrificio y las variadas añoranzas por el padre}

\section{El sacrificio y la falta del otro}

En el corpus freudo-lacaniano, marco conceptual desde el cual realizo mi análisis, no hay una teoría sistemática del sacrificio; hay una teoría sistemática del Padre, de la cual el sacrificio no es sino una de sus consecuencias.

Sostenemos la hipótesis de que en psicoanálisis las paradojas del padre conducen necesariamente a las del sacrificio. El sacrificio está indisolublemente ligado a los Nombres del Padre y sus paradojas, es decir, refiere a las faces del goce del padre (pére-versión) y esto porque la conjunción de la ley con el deseo no discurre sino encabalgada a "la suposición del goce puro del padre" (Lacan, 20/11/63).

En el Seminario inconcluso "Los Nombres del Padre” Lacan avanza en su teoría del sacrificio al abordar "la Akedá (ligadura), el sacrificio de Isaac...” en relación a la inconsistencia del Otro. Para profundizar el tema trabaja, en el citado seminario, dos mitos: el mito moderno de Tótem y Tabú de Freud; y el texto mítico sobre el sacrificio de Abraham.

Es preciso confrontar los dos mitos: en el primero se trata del padre muerto destacándose la cuestión del parricidio; en el segundo, la del sacrificio del hijo, lo que remite, sin embargo, también a la muerte del padre... el primordial (urvater), en ambos del parricidio y del sacrificio se trata. Articulando los dos mitos puede advertirse la bifurcación, en relación al padre, de deseo del Otro y goce del Otro, tema que abordaremos insistentemente en estos capítulos. 


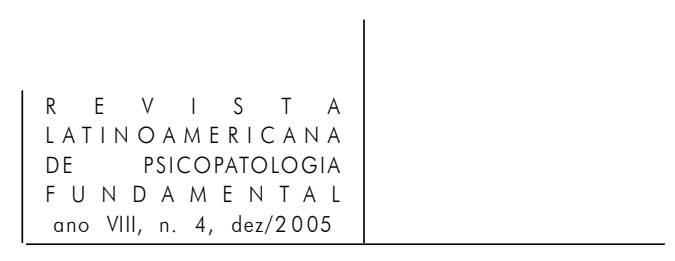

Recordemos que Freud traza los ejes fundamentales del sacrificio en Tótem y Tabú al afirmar que el ofrecimiento sacrificial del hijo no es sino una celada al padre, pues implica cesión de responsabilidad en el asesinato: es el Otro el que lo pide, lo ordena o lo exige. Por eso, en la alianza culposa, los hijos han quedado libres de cargo y responsabilidad respecto al anhelo parricida... el sacrificio será su coartada.

Como intento de pacificar a Dios padre por el crimen cometido contra Él, el sacrificio muestra - según Freud - el lazo de alianza y reciprocidad que une a un sujeto, a un grupo o a un pueblo con la divinidad. Pero, al depositar en Dios el pedido del sacrificio, lo que se trata es de implicarlo en un goce que aplaque la deuda imposible de saldar: el goce parricida. Así, no son los hijos los responsables del sacrificio, es Dios padre quien lo ha ordenado e instituido.

En 1938 - Moisés y la religión monoteísta - las paradojas de la ley del padre conducen a Freud, nuevamente, a las del sacrificio: siendo el padre el que vehiculiza la ley de la palabra, será justamente la inconsistencia de esa misma ley la que convoque al cruel sometimiento del hijo. Este desarreglo incurable del padre conlleva el goce superyoico desde la intersección de culpa y sacrificio.

La culpa, enlazada al sacrificio, da cuenta de un rebrote pulsional. El sometimiento a la voluntad de Dios padre, de alguna manera, degrada el progreso de la espiritualidad en tanto sirve "a los secretos propósitos del castigo", esto es, al goce masoquista. Goce que, muchas veces, conduce al sujeto y a los pueblos a su aniquilamiento bajo la hórrida convicción de que así lo pide el padre en su versión de amo impío.

Pese a la ley sublime del padre - es decir, su deseo - que hace posible el "progreso de la espiritualidad", queda siempre un remanente de goce... una procura de sangre que, al ser adjudicada a Dios padre, ofrece la coartada perfecta para la lógica sacrificial de sus seguidores: constantemente la inmolación al acecho por una deuda con el padre que se paga, en lo simbólico, con la palabra y sus sucedáneos de la permutación; y en lo real, con un ofrecimiento que implica cuerpo y goce.

Doble inscripción - en los descendientes - del padre y de la deuda: la una, pura espiritualidad en la dimensión simbólica de sustitución; la otra, traumática como fijación pulsional. Paradojas del padre que conducen a las del superyó; a ese saldo de la espiritualidad que, como nombre perverso del padre, presentifica justamente eso que pretende desechar: el retorno pulsional.

También la culpa, en la variedad de sus registros (Real, Simbólica e Imaginaria), arrastra aquella dualidad de lazo amoroso y fascinación sacrificial que, como retorno pulsional, invierte la tentación parricida: no es el hijo el que anhela la muerte del padre, sino que el subterfugio del sacrificio achaca al padre la exigencia de la inmolación sacrificial del hijo, o de los hijos del hijo. 


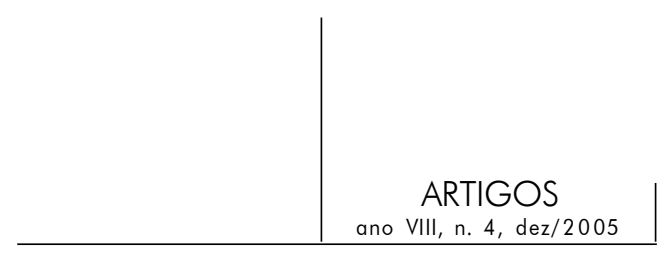

Formulaciones freudianas del sacrificio que se anudan a las del superyó y que encuentran su nexo con la culpa reveladora de esa tentación de ofrecimiento sacrificial al padre, reverso mismo del anhelo parricida. El sometimiento del yo al superyó implica una renuncia pulsional cuyo saldo no se traduce en pacificación sino en hostigamiento, pues, justamente, la potenciación de esa renuncia deviene retroalimentación de la erotización de la pulsión de muerte. La culpa se hace sometimiento y la alianza amorosa con el padre troca en temor y fascinación sacrificial - saldo masoquista inevitable de toda filiación.

Freud no se engaña. Una culpa que para ser expiada precisa del suplicio del hijo es porque encubre el anhelo asesino hacia el padre; así, la tentación sacrificial del hijo se enlaza al pago por su deseo parricida.

Para Lacan - que retoma estos desarrollos freudianos - el lugar que los hombres otorgan a Dios como padre no es el lugar del Otro, del Otro del significante; sino, más bien, el del Otro inconsistente, el de la falta $S(\mathbb{A})$ - que refiere a la castración y al objeto $a$ como resto, como real. En torno a este real circulan los Nombres del Padre tratando de cernirlo. Tarea siempre tantálica; de ahí su pluralización: no es posible reducir los Nombres del Padre a la metáfora paterna.

El abordaje que hace Lacan del sacrificio en el Seminario inconcluso Los nombres del Padre permite una nueva lectura, no sólo del mito bíblico de la Akedá de Isaac, sino también del mito moderno de Tótem y tabú y del de Edipo.

Los variados mitos y el goce del padre

En los Seminarios “El reverso del psicoanálisis” (1969-70) y "De un discurso que no fuera semblante" (1971) Lacan hace una lectura après-coup del Edipo del Seminario de la Ética (1959-60). Constituyen un punto de apoyo crucial para esa lectura tanto sus avances sobre el objeto $a$ del Seminario de La Angustia (1962-63) como la versión del goce del padre del Seminario inconcluso de 1963. Dirá en 1971:

Me parece imposible - no es en vano que tropiezo de entrada con esta palabra - no entender la esquicia que separa el mito de Edipo de Tótem y tabú. Muestro enseguida mis cartas: el primero está dictado a Freud por la insatisfacción de la histérica, y el segundo por sus propios impasses. Ni del niño, ni de la madre, ni del trágico pasaje del padre al hijo, ¿qué pasaje? Si no es el del falo. De lo que fue el tejido del primer mito ni una huella en el segundo. Allí, en Tótem y tabú el padre goza, términos que están velados en el primer mito del goce. El padre goza de todas las mujeres hasta que sus hijos lo abaten poniéndose en ese lugar con un acuerdo previo, después del cual ninguno lo sucede en su 


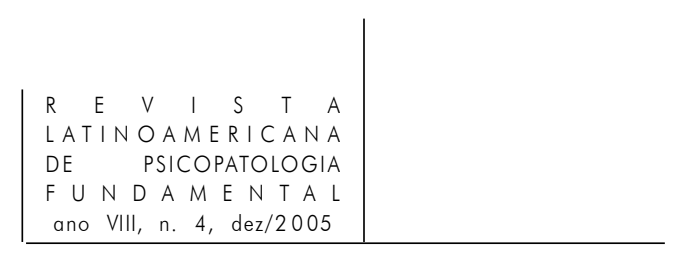

glotonería del goce. El término se impone por lo que pasa de retorno: los hijos lo devoran, cada uno no teniendo necesariamente más que una mujer y, por este hecho mismo, el todo haciendo una comunión. Es a partir de ahí que se produce el contrato social. (Lacan, 1971. Sesión del 9/6/1971)

Pero, ¿qué pasa con esa "glotonería de goce del padre”? ¿acaso el contrato social la elimina? Sabemos que no, y para dar cuenta de la división de la que hablamos antes entre el deseo y el goce del Otro es que Lacan interroga el sacrificio de Abraham.

Dijimos que el Otro de la falta $S(\mathbb{A})$ - no es el Otro en tanto que padre muerto: un elemento heterogéneo y consistente que resta de él tiene que ver con el goce y la causa del deseo. El Dios de Abraham muestra esa dualidad al exigir el sacrificio de lo más preciado, del hijo de la promesa. En el capítulo siguiente vamos a detenernos en ello.

Veamos ahora el pasaje desde el mito Edípico (del cual se desprende el Nombre del Padre, padre muerto vinculado al complejo de castración: el padretodo-amor) hacia el mito del sacrificio de Abraham (del que se desprenden Los Nombres del Padre, una pluralización de esos Nombres que intentan, en asíntota, cernir la oquedad del Otro de la falta $\mathbb{A}$ ). Este pasaje da cuenta del fracaso de la metáfora paterna y de la inconsistencia del padre.

Por ello, a partir de 1962, Lacan resalta que las variadas añoranzas por el padre pueden hacerse por dos vías diferentes: por el sacrificio de amor como don, y por la fascinación del sacrificio. En suma, respuestas al Padre como significante que es muerto, y también al padre glotón de goce que impele a la inmolación sacrificial.

En "Subversión del sujeto", afirma que se puede probar que el Otro existe por las vías del amor, pero también puede cubrirse "ese goce cuya falta hace inconsistente al Otro" (1960, p. 800) haciéndose cargo de la culpa y el sacrificio. "Recordatorios de goce" en las que el sujeto procura ofrecerse al Otro por la vía del don... o paga con el bien más preciado: la vida.

En esta dirección hay que puntualizar que el matema $S(\mathbb{A})$ refiere no sólo al significante que falta, al significante innombrable y a la castración; sino también a ese agujero que sólo consiste como objeto $a$.

El Otro, en su inconsistencia, no sólo no brinda significancia, sino que falla desde lo real. Como dice Michel Silvestre: “... el Otro tachado no sólo no contiene el objeto, sino que hay un agujero en el Otro: $\mathrm{S}(\mathbb{A})(\ldots)$ y (..), por ese agujero, el Otro huye: (...) finalmente el Otro no existe” (1988, p. 210).

Extraños los caminos de la subjetividad para hacer existir al Otro ( $\mathbb{A})$, tan extraños y enigmáticos como el camino recorrido por Abraham en la ascensión al monte Moriah para la Akedá del hijo de la promesa. 


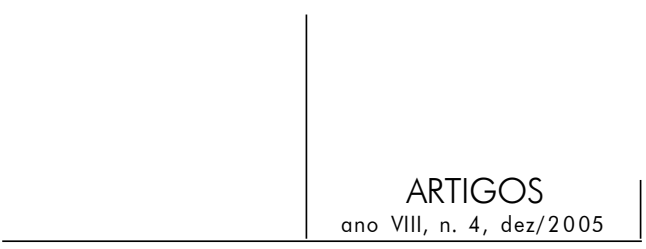

Si la falla en el Otro - S(A ) - refiere tanto al límite de la significancia y de la castración como al que impone el objeto a desde su agujero en lo real, entonces, a partir de la tachadura del Otro, surgen dos interrogantes que marcan las distintas direcciones del sacrificio:

a) Por un lado, desde el límite a la significancia y de la castración surge el interrogante del sujeto: ¿Qué(me) quiere el Otro? - ¿Puedes perderme? - que remite a ¿Qué quiere decir(me) el Otro?, o, a ¿Qué lugar tengo en el deseo del Otro?

b) Por otro lado, desde el litoral de lo real surge un interrogante más atroz: ¿Por qué es tan peor, quiere gozar(me)? ¿Puedo arreglar su falla con mi ofrecimiento sacrificial, con la mortificación de mi cuerpo, con mi suplicio?

Así, el sacrificio pretende, con un sólo movimiento, realizar dos operaciones: captar la falta del Otro y, al mismo tiempo, encubrir dicha falta. Si el sacrificio “está destinado a la captura del Otro en las redes del deseo” (Lacan, 1962/63. Sesión del 6/6/63), esa ofrenda garantiza que el Otro existe y que el sujeto no le es prescindible. Aunque conviene destacar que es posible responder con el sacrificio a la falta en el Otro ora desde el deseo, ora desde el goce.

Me detendré en esta cuestión siguiendo el análisis que hace Lacan del texto mítico del sacrificio de Abraham.

\section{El sacrificio de Abraham e Isaac y las paradojas del padre}

Lacan precisa acudir al mito del sacrificio de Abraham para dar respuestas a las paradojas de Los Nombres del Padre y a la cuestión del fracaso de la metáfora paterna. Desde allí acabará reconociendo que no es posible reducir los Nombres del Padre a dicha metáfora.

Tomemos, entonces, el texto mítico y las referencias que ofrece en el Seminario inconcluso de 1963: Génesis XXII, el cuadro de Caravaggio - que algunos fechan de 1603 - “El sacrificio de Isaac”, “Temor y Temblor” de Kierkegaard y "El ritual” de Theodor Reik. Agreguemos los textos: "Mensajeros de Dios - Relatos y leyendas bíblicas” de Elie Wiesel, “Dar la muerte” de Derrida y "Pasión intacta” de George Steiner.

Cabe destacar que, la Akedá de Isaac, recibió innumeras traducciones, interpretaciones, exégesis, comentarios, glosas, y subversiones. Destacaremos de ellas cinco secuencias - que toman como referencia básica los textos antes citados - para ofrecer nuestra versión del mito, la estructura de ficción que le otorgamos desde la lectura de Lacan, y para obtener un rédito clínico de esa seriación. 


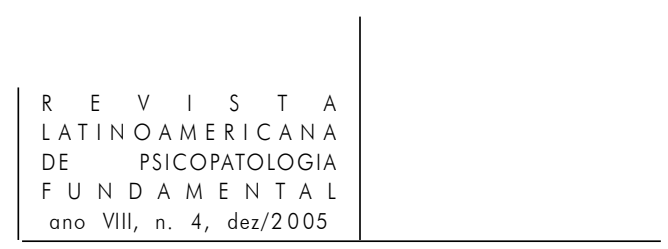

Primera secuencia: padres e hijos - verdugos y víctimas

Dios tienta a Abraham $^{1}$ poniendo a prueba su fe. Le pide la Akedá de Isaac, el sacrificio del hijo más amado y procurado.

Veamos esta secuencia en Gén. XXII en la traducción castellana del hebreo:

1. Aconteció después de estas cosas que Elohim probó a Abraham, diciéndole: - Abraham, y dijo: - Heme aquí.

2. Y dijo: - Toma, por favor, a tu hijo, a tu único, a Itzjac a quien amas y vete [para ti] a la tierra de Moriah; y elévalo allí en holocausto sobre uno de los montes, que Yo te diré.

3. Abraham se levantó muy temprano en la mañana. Aparejó su asno, tomó consigo a dos de sus siervos, y a Itzjac su hijo; partió leña para el holocausto, y levantándose, fue al lugar que Elohim le dijo.

4. Al tercer día Abraham alzó sus ojos y divisó el lugar de lejos.

5. Entonces Abraham dijo a sus siervos: - Esperad aquí con el asno, en tanto yo y el muchacho iremos hasta allá; adoraremos y volveremos a vosotros.

6. Abraham tomó la leña del holocausto y la puso sobre Itzjac su hijo, y tomó en su mano el fuego y el cuchillo; y caminaron los dos juntos.

7. Entonces Itzjac dijo a Abraham su padre: - Padre mío... Y respondió: - Heme aquí, hijo mío. Y dijo: - He aquí el fuego y la leña, pero ¿dónde está el cordero para el holocausto?

8. Abraham respondió: - Elohim se proveerá el cordero para el holocausto, hijo mío. Y caminaron los dos juntos.

Abraham responde dos veces "Heme aquí": una a Elohim (uno de los nombres de Dios) y una a su hijo. Este "Heme aquí" a la pregunta de Isaac por el cordero para el holocausto da cuenta de su total disposición a cumplir con el pedido de Dios; como si dijera: "Heme aquí - en conjunción con Dios - dispuesto a cumplir con la prueba". Abraham está dispuesto a abandonar su lugar de padre de la ley, he allí su dualidad.

Sin embargo, cuando Elohim pidió el holocausto de Isaac, Abraham no respondió "Heme aquí". No respondió nada. Fue a su casa en silencio, se acostó y se quedó dormido. Luego que transcurrieron cuatro noches, en la mañana inició con Isaac el camino de la prueba a la que Dios lo sometía. Abraham marchaba como verdugo, Isaac como víctima; pero el lugar de verdugo fundamental lo tomaba Dios; Abraham e Isaac ocupan el lugar de víctimas. ¿Por qué ese ofrecimiento: uno como víctima activa - cómplice de ese crimen -, el otro como víctima pasiva? ¿Por qué esa conjunción de ambos con el goce de Dios?

1. Génesis 17, 3-6 (Ab: padre/ ham: pueblo = Ab-ha-ham (padre [de] el pueblo: Padre de Pueblos). 


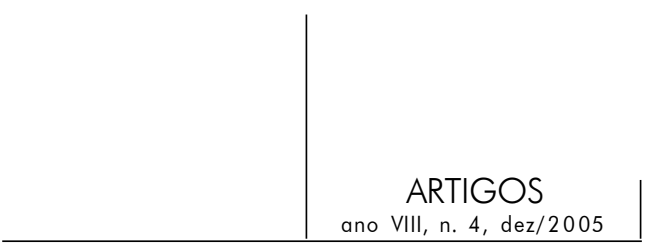

Más adelante indagaremos este enigma.

En este punto son importantes las puntuaciones de Kierkegaard y Derrida en torno al silencio de Abraham y las diferencias que trazan entre éste y el héroe trágico.

El héroe trágico puede hablar, compartir, llorar, quejarse. No conoce "la terrible responsabilidad de la soledad”. Agamenón puede llorar y quejarse con Clitemnestra e Ifigenia. "Las lágrimas y los gritos apaciguan". Hay un consuelo. Abraham no puede empero ni hablar, ni compartir, ni quejarse. Está absolutamente incomunicado. (Derrida, 1999, p. 74)

En ese momento Abraham no habla ninguna lengua humana, recalca Kierkegaard.

En el Seminario inconcluso "Los Nombres del Padre” y en referencia al goce del Otro, Lacan interroga: “... quien hay más allá, del cual el sujeto cada vez que habla toma la voz?” (20/11/1963), y agrega que lo inevitable de la pregunta explica que Freud ubique al mito del asesinato del padre en el centro de su doctrina. ¿Por qué? Recordemos que entre los griegos los actores trágicos usaban máscaras que amplificaban la voz y otorgaban al actor, a veces, el carácter sagrado de representante de los dioses. La propia voz de un hombre se convertía en sostén de la voz inaudible e inaudita de Dios.

Si Abraham como verdugo se convierte en sostén de esa voz inaudible e inaudita de Dios, ya no puede hacer circular su palabra por la lengua humana. Algo de goce deberá perder para que pueda, nuevamente, hablar a su hijo.

\section{Segunda secuencia: rehusar el goce}

En el momento en que Abraham va clavar el cuchillo en el cuello de Isaac - el cuadro de Caravaggio lo escenifica -, el enviado de Yahvé detiene su mano, le ordena rehusarse el acto (versagung), renunciar a acceder al goce de Dios, retractarse de colmar el goce de Dios: ruptura de promesa con ese goce.

"Lo que Elohim le designa a Abraham para sacrificar en el lugar de Isaac es su antepasado, el dios de su raza. Aquí se marca la línea divisoria entre el goce de Dios y lo que una tradición le asigna como deseo, deseo de algo de lo cual se trata de provocar la caída” (Lacan, 20/11/63).

Siguiendo a T. Reik especificará Lacan que Isaac, como objeto del sacrificio, será sustituido por el morueco - carnero-padre o que ha servido para la reproducción - el cual, trabado por sus cuernos en un matorral será ofrecido como víctima. Ese animal no es sino el ancestro del pueblo de Abraham: el padre de la horda, el padre anterior a la prohibición del incesto. Así, el sacrificio del padreanimal sustituye al sacrificio del hijo sellándose la alianza de Abraham con Elohim. 


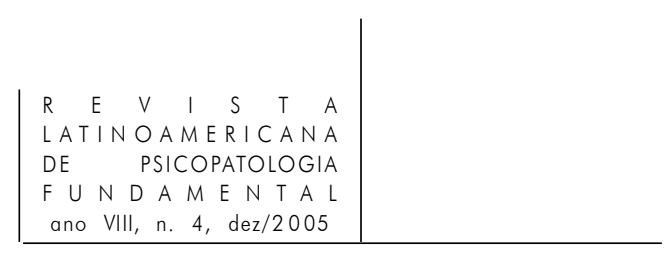

9. Cuando llegaron al lugar que Elohim le había dicho, Abraham edificó allí un altar, arregló la leña; y ató a Itzjac su hijo y lo puso sobre el altar, encima de la leña.

10. Abraham extendió su mano, y tomó el cuchillo; para degollar a su hijo.

11. Entonces lo llamó el enviado de Hashem desde el Cielo diciendo: - ¡Abraham! ¡Abraham! Él respondió: - Heme aquí.

12. Y dijo: - No extiendas tu mano sobre el muchacho, ni le hagas nada; porque ahora conozco que veneras a Elohim, ya que no Me has rehusado tu hijo, tu único.

13. Entonces Abraham alzó la vista y miró, y he aquí un carnero [otro] [luego] está trabado por sus cuernos en un matorral; Abraham fue, tomó el carnero y lo ofreció en holocausto en lugar de su hijo.

El óleo de Caravaggio "El sacrificio de Isaac”, que se conserva en la Galleria degli Uffizi de Florencia, muestra un joven Isaac (no un niño) invadido de terror. La boca abierta indica la queja, el grito, la desesperación o la súplica. Su anciano padre lo sostiene firmemente por el cuello dispuesto a cumplir el pedido de Dios. Abraham empuña con fuerza el cuchillo, puede notarse la tensión en su brazo y, en oposición, la del Ángel que lo detiene. Ese Ángel está suspendido en el aire, casi estático, y señala al carnero que sustituirá a Isaac en el holocausto y al cuerno desprendido que se convertirá en el shofar. Abraham le dirige una enigmática mirada que condensa todo el misterio de la escena.

\section{Tercera secuencia: la bendición y el resto incontorneable}

En la segunda secuencia habíamos destacado una sustitución, una metáfora: en lugar de Isaac aparece el morueco que se ofrecerá en sacrificio a Yahvé. En don a su fe Yahvé predice a Abraham una posteridad numerosa. Porque no cuestionó el mandato de Dios obtendrá la bendición de una akedá - ligadura - a la ley de los Nombres del Padre que le promete vida y sucesión de generaciones. Pero esto no es suficiente, el don no permite contornear todo lo real del goce de Dios, hay ligadura pero también hay sacrificio... siempre el pedido de un plus:

14. Abraham llamó el nombre de aquel lugar Hashem-Irhé; por eso se dirá perpetuamente: "En el monte de Hashem se manifestará."

15. El enviado de Hashem llamó a Abraham; por segunda vez desde el Cielo,

16. y dijo: - He jurado por Mí mismo, dice Hashem, que porque has hecho esto, y no Me has rehusado tu hijo, tu único,

17. de cierto te bendeciré y en gran manera multiplicaré tu descendencia como las estrellas del cielo, y como la arena que está en la orilla del mar; tu descendencia poseerá los portones de sus enemigos. 


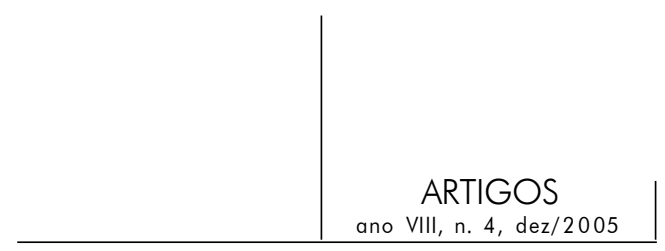

18. En tu descendencia serán benditas todas las naciones de la tierra; por cuanto obedeciste mi voz.

19. Abraham regresó a sus siervos, y levantándose caminaron juntos a BeerSheva; y Abraham se asentó en BeerSheva.

Las faces (versiones) de Dios determinan, para Lacan, los Nombres del Padre y la posible alianza con la ley. Uno de esos nombres es el morueco, aquel que será llevado al sacrificio y cuyo resto es el cuerno. En Génesis XXII son variados los Nombres de Dios: Elohim, Yahvé, Sadday, Hashem, a los que se agrega (según Lacan) el morueco.

Los rabinos del Midrasch se interesaron mucho por ese morueco. Para algunos el morueco primordial fue creado el sexto día, o sea, antes del hombre; es, entonces, el antepasado del hombre, pero es también, en cierto modo, el antepasado del Dios único.

Algo tenía que morir de Dios, como padre primordial, como padre gozador, para que surgiera la ligadura, la alianza del Dios del deseo con Abraham. Pero quedaba un resto que no era posible aniquilar: quedaba el cuerno. ${ }^{2}$

También rabinos del Midrasch indagaron por esos restos del objeto de sacrificio. "Ninguna parte de aquel morueco resultó inútil”, dijo un tal Rabí Hanina, puesto que hicieron variadas cosas con las cenizas, los nervios, la piel, las pezuñas, hasta con los cuernos del animal. Del cuerpo de ese morueco resta el shofar, el cuerno primitivo que, por un lado, sugiere los gritos del animal que están matando, y al mismo tiempo conmemora la Akedá como obediencia a la voz de Dios y la alianza con El. El shofar no es sino la voz de Dios mismo, ese real que queda como resto luego de su asesinato, de su holocausto.

2. Es interesante recordar aquí la costumbre del sacrificio pascual referida en Éxodo 23.18 ("No ofrecerás la sangre de Mi sacrificio pascual junto a pan fermentado, ni se dejará el sebo del sacrificio de Mi solemnidad hasta la mañana.”) - reiterado casi textualmente en el decálogo cultual de Ex. 34.25. Según ella los israelitas ofrecieron el sacrificio por primera vez en la noche de la huida de Egipto para evitar al Ángel vengador. Se sacrificó un cordero y con su sangre se untó el vano de las puertas para evitar, precisamente, la muerte de los primogénitos. La costumbre, practicada por una pequeña secta de judíos en las localidades de Siquem y Holon de la Samaria actual, tiene varias aristas con lo que hemos estado tratando: los corderos son desollados antes del anochecer y asados enteros en hoyos profundos donde arden matorrales (recordar el matorral donde el morueco engancha sus cuernos) y luego son consumidos por todos los miembros de la comunidad - vestigios de comida totémica. Por lo demás, y es en lo que se apoyan los que sostienen que los israelitas primitivos continuaban practicando el sacrificio de niños canaanita, Ex. 34.19 dice “Todo primer nacido es Mío, asimismo todo primerizo de tu ganado que fuere macho...” 


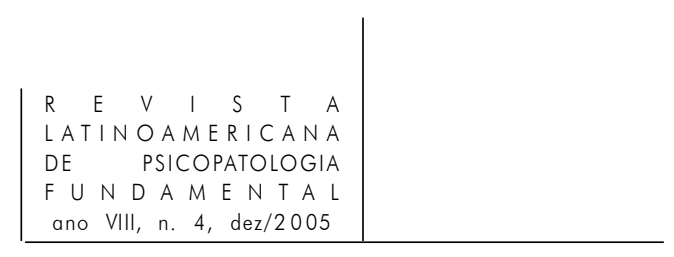

Theodor Reik (1928) remarcará que el shofar funciona en el ritual que recuerda la alianza de Dios con su pueblo, y también en la culpabilidad del pueblo para con su Dios por el asesinato perpetrado por Abraham - Padre de Pueblos contra el cordero primordial. El shofar, cuerno que resta de ese Dios vivo, el cuerno del morueco. Atendiendo a las hipótesis freudianas de Tótem y Tabú, aseverará Reik que el morueco es la representación del urvater y, de esa manera, es la voz del padre asesinado la que resuena con el llamado del shofar, conmemorando la deuda contraída por el pueblo con su Dios.

Para Reik el shofar se convirtió en la promesa de expiación del hecho primitivo:

... no debemos olvidar que el ritual del shofar, que significa - como la comida totémica - la expiación del antiguo asesinato original, al mismo tiempo brinda la oportunidad para su rememoración. En la imitación de la voz de Dios, en la usurpación del cuerno divino, el símbolo más sobresaliente del dios totémico, se vuelve a cometer el pecado in nuce. La razón por la que se debe tocar el shofar varias veces - el día de Año Nuevo, treinta veces - obedece a la fuerza de impulsos inconscientes que tienden al parricidio y a la intensidad de aversión a ellos. (Reik, 1928, p. 329)

La bendición, el pacto simbólico con Dios padre no es sin resto ni máculas, la voz de Dios ha de resonar lastimera y laceradamente ya sea por el camino del ritual, ya sea por sus litorales bajo el acecho del goce parricida.

Kierkegaard sugiere la akedá de Isaac como un sueño de Abraham, el sueño por excelencia, que consolida el valor de mito que tiene tal sacrificio. Sueño que anida en toda subjetividad y por ello convoca a su análisis: el lugar del padre desliza siempre un pedido imposible... una respuesta imposible, tal su indeterminación y su enigma. En torno a ello se construye el lugar del hijo.

Cuando Abraham, sobre su asno se halló solo en Morija, la tarde era apacible; se arrojó de cara contra la tierra y pidió perdón a Dios por su pecado, perdón por haber querido sacrificar a Isaac, por haber olvidado su deber de padre hacia su hijo. Tomó de nuevo, con más frecuencia, el camino solitario, pero no halló reposo. No podía concebir como pecado haber querido sacrificar su más preciado bien, aquél por quien hubiera dado su vida más de una vez, a Dios; y si era un pecado, si no había amado a Isaac hasta ese punto, no podía comprender entonces cómo podía ser perdonado; porque ¿hay pecado más terrible? (Kierkegaard, 1991, p. 15-6)

Si bien, como afirma G. Steiner, Kierkegaard escribe Temor y Temblor en relación a la traición amorosa de Regina Olsen y a la muerte de su padre, no deja de insistir allí en una culpa paterna imperdonable que termina revirtiendo, implacablemente, sobre el hijo. Es por esto que la versión de Kierkegaard de 


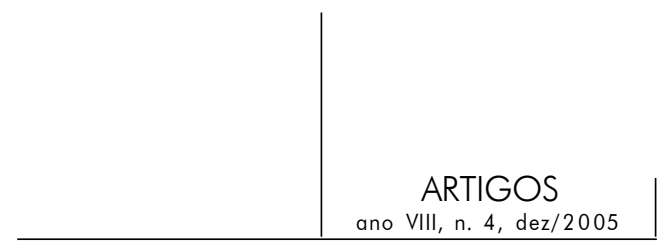

Génesis XXII por un lado muestra, y por otro encubre, las faltas del padre: el padre que presenta es un padre grandioso e idealizado aunque por momentos se torne diabólico.

El padre de Kierkegaard había maldecido a Dios.

La distante maldición se convirtió en una obsesión para toda la vida. En un estado de ánimo propio del “calvinismo lamarkiano”, Kierkegaard se convenció a sí mismo de haber heredado aquella cicatriz del anagrama y de ser, inexorablemente, objeto del castigo divino. Se hace palpable una cierta manera de cultivar a propósito el terror, así como un drama trágico psicodoctrinal.

En la doble sombra de su infidelidad y condición de paria, por una parte y el pecado heredado de la blasfemia del padre, por otra parte, Kierkegaard pudo, como ningún otro pensador o exégeta, construir su propio Génesis XXII. (Steiner, 1997, p. 315-6)

La akedá de Isaac no sólo puede pensarse como un sueño de Abraham, sino también como un sueño y un fantasma de Kierkegaard, de Freud, de Lacan y de todos aquellos que intentamos balbucear en torno a los enigmas de la ley, del padre y la filiación. Cada uno construirá - a su modo - su propio Génesis XXII. Fantasma nodular de la subjetividad en torno al enigma de la paternidad, tal su saldo clínico.

Cuarta secuencia: la orden imposible de Dios

Dios, como afirma Derrida, da una orden doblemente imposible: por un lado porque pide lo peor; por otro, porque se retracta de esa orden imposible.

Lacan se inspira en Kierkegaard para decir que lo que lleva a Abraham a interrogar el deseo de Dios, es su propia angustia, la cual, enfrentada a la falta del Otro, interroga esa falta.

Lacan construye dos versiones de Dios: en una hace un pedido imposible, en la otra le ofrece una bendición como don por su creencia y su amor. La primera está del lado del goce, la otra del lado del deseo.

Para Elie Wiesel la misión de Abraham era servir como mensajero de Dios entre los hombres demasiado vanos y ciegos para reconocer Su gloria. La tradición lo pone por encima de Moisés, cuya ley observaba; inclusive por encima de Adán, cuyos errores se le encomendó corregir.

Abraham, el primer enemigo de la idolatría, el que debía abandonar a su padre fabricante de ídolos, el primero en desmitificar los tabúes oficiales y suspender las prohibiciones rituales, ¿por qué justamente él obedece un pedido imposible?, ¿por qué justamente él está dispuesto a reinstaurar la idolatría y el ritual prohibido? ¿cuál la razón de su secreto? En otras oportunidades se atrevió a interrogar a Dios y Dios escuchó y respondió, ahora, en cambio, Abraham guarda silencio. 


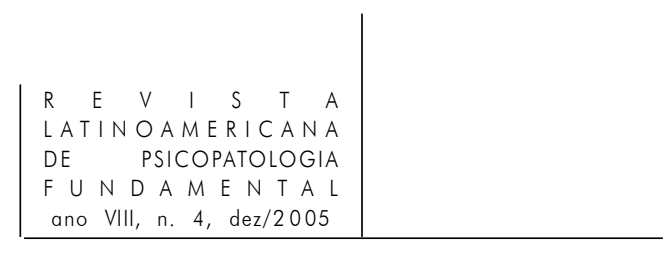

Dios perdonó todo a Abraham, inclusive, sus preguntas sobre la supuesta inclemencia divina contra Sodoma y Gomorra.

Abraham, como hijo fiel de Dios, acata sus mandamientos.

Para poner a prueba su voluntad y su clarividencia, Dios le había hecho dejar la seguridad del hogar paterno, desafiar a los gobernantes y precipitar a sus ejércitos en la batalla, sufrir el hambre y el exilio, la desgracia y el fuego. Su fe en Dios nunca se conmovió. Era tan leal a Dios que fue recompensado con un hijo que se convirtió en símbolo y portador de la gracia y la bendición para las generaciones futuras. (Wiesel, 1989, p. 61)

Ese hijo de la promesa, Isaac, le fue dado cual una bendición (Baraká) ${ }^{3}$ y reafirmación del lazo de filiación y genealogía con su pueblo.

Al obedecer el pedido imposible de Dios, Abraham hace existir a Dios, a pesar de los reproches que le tiene por su inclemencia. Aunque sea por la vía del temor puede seguir contando con su paradójico amparo. Es posible ver esta procura de consistencia desde Dios, desde Abraham y, aun, desde Isaac:

a. Desde Dios: ¿Por qué Dios hace un pedido imposible? Justamente Dios, que conocía y respetaba las leyes y los mandamientos de su Torah, el Dios que está obligado a obedecer su propia ley y, porque lo sabía todo, no desconocía que matar estaba prohibido; más aún, que matar mutilaba la palabra misma de Dios. ¿Cuál el goce de Dios para hacer semejante requerimiento? Con ese pedido imposible, Dios pretende encubrir la inexistencia de Dios: sólo la falta de Dios

3. Génesis XVII: 2. Y pondré Mi pacto entre Mi y ti, y te multiplicaré mucho. 3. Y Avra-m cayó sobre su rostro, y Dios habló con él diciendo: 4. "En cuanto a Mi, he aquí MI pacto contigo, y serás padre de una multitud de naciones. 5. Y no se llamará más Abra-m tu nombre, sino que Avr-ha-m será tu nombre, porque te he hecho padre de una multitud de naciones. Y Génesis XVII: 15. Y Dios dijo a Avra-ha-m: "A Sa-ray, tu mujer, no la llamarás con el nombre de Sa-ray, pues Sa-rá será su nombre. 16. Y Yo la bendeciré, y de ella también te daré un hijo; y la bendeciré, y ella vendrá a ser (madre) de naciones; reyes de pueblos procederán de ella”. En la Biblia es muy importante la cuestión de las Promesas divinas y la Alianza, donde Yahvé le dirige la palabra a Abraham y le promete el hijo. A partir de la Alianza es nombrado: Abraham, antes Abram (Ab: padre/ham: pueblo = Abraham: Padre de Pueblos), hay una nueva producción: - Hay una nueva nominación (Abram®Abraham; Sarai ${ }^{\circledR}$ Sara).

- Aparece la Alianza posibilitada por el Pacto.

- Y ese Pacto implica un corte: la circuncisión

- La promesa del Hijo, o sea, la posibilidad que Abraham pague su deuda simbólica y en este punto el Nombre de Dios que aparece es El Sadday, el que establece la alianza con Isaac y con Jacob.

Luego de la muerte de Sara el patriarca Abraham se mostrará como un Genitor, se casará y tendrá 5 hijos, pero no son los hijos que recibirán la Baraká (Bendición). 


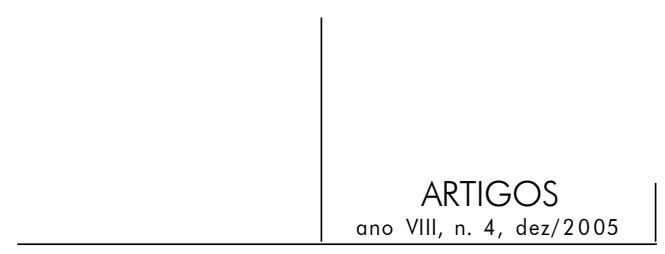

puede precipitar a Dios a sacrificar su ley, su palabra y su promesa. Por eso, es preciso hacer existir a Dios cayendo en la idolatría y en el ritual pagano del sacrificio del hijo, Dios vs. Dios. Para sostenerlo es necesario recuperar al Dios maligno, aquel que osa romper su propia ley y su estirpe. El deseo de Dios confrontado a los Goces de Dios: así procura Abraham la consistencia de Dios.

b. Desde Abraham: Abraham, ¿cuál su goce para acatar el mandato de Dios sin interrogarlo? ¿obedecer a Dios y matar al hijo de la promesa, ese que aseguraría no sólo su propia genealogía y filiación, sino también la genealogía de un pueblo? Abraham, en su angustia, interroga - según Lacan - la falta en el Otro y responde al Padre Dios, al Padre de la ley con la obediencia a esa ley, al mismo tiempo que mancillando esa ley. Para hacer existir a Dios Padre es preciso presuponerlo tan peor, tan vengativo, tan malvado. Para acallar su tentación parricida por las faltas de Dios, las múltiples faltas e inclemencias que le reprochaba desde Sodoma y Gomorra, tenía que ofrecer su propio sacrificio presuponiendo que era Dios quien lo ordenaba. Y es en el Monte Moriah donde Abraham, finalmente, dará rienda suelta a su anhelo parricida asesinando al urvater, al morueco, al padre primordial que muestra una de las faces de Dios.

Una de las versiones de Kierkegaard - donde desliza su propia tentación sacrificial en el anhelo de recuperar a un padre consistente - permite ampliar nuestra aseveración:

Y Abraham se decía: "Pero no puedo ocultarle por más tiempo adónde le conduce este andar”. Se detuvo, apoyó su mano sobre la cabeza de su hijo para bendecirlo, e Isaac se inclinó para recibir la bendición. Y la faz de Abraham era la de un padre; dulce era su mirar, y su voz exhortaba. Pero Isaac no podía comprenderle, su alma no podía elevarse tanto; se abrazó a las rodillas de Abraham, se arrojó a sus pies y clamó por la gracia; imploró por su juventud y sus dulces esperanzas; habló de las alegrías de la casa paterna, evocó la soledad y la tristeza. Entonces Abraham lo levantó, lo tomó de la mano y se puso en camino y su voz exhortaba y consolaba. Más Isaac no podía comprenderle. Abraham trepó por la montaña de Morija; Isaac no le comprendía. Entonces se apartó Abraham por un momento del lado de su hijo, y cuando de nuevo miró Isaac la faz de su padre la halló cambiada, porque el mirar se le había hecho feroz y aterradoras las facciones. Agarró a Isaac por el pecho, lo arrojo por tierra y gritó: “¡Estúpido! ¿Crees tu que soy tu padre? ¡Soy un idólatra! ¿Crees tú que obedezco al mandato divino? ¡Hago lo que me viene en gana!” Entonces Isaac se estremeció, y exclamó en su angustia: “¡Dios del cielo! ¡Ten piedad de mí! ¡Dios de Abraham! ¡Ten piedad de mí! ¡Sé mi padre, ya no tengo otro en esta tierra!” Pero Abraham se dijo muy quedo: "Dios del cielo, yo te doy las gracias; vale más que me crea un monstruo antes que perder la fe en ti”. (Kierkegaard, 1991, p. 13-4) 


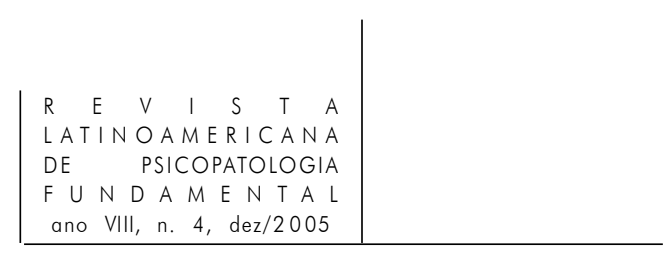

En el mito de Abraham se desliza su angustia, su intento de otorgar existencia al Otro en tanto Dios, así como el propósito de obtener un lugar en el deseo de ese Dios padre y de la ley que él obedece.

Un padre con mirada dulce y portador de palabras que exhortan, padre de la bendición (Baraká) que ningún hombre alcanza a inscribir del todo; padre Dios que no consigue erigirse plenamente en sostén de la ley; padre que, aunque presente, no logra evitar el desamparo... y allí, la angustia. Padre Dios que, aunque otorgue al sujeto un lugar en su deseo, no le ofrece plena garantía de su existencia. Tampoco ofrece garantías contra el anhelo parricida de Abraham por esas faltas, quien ha de fabricar - para darle consistencia a Dios, un padre del puro capricho, de la ley insensata del goce - un padre que se presentifica vociferando y exigiendo el goce: “¡Sacrificarás al hijo de la promesa! Porque ese es mi goce, mi extravío!"

¿Puede haber un padre más consistente que ese en lo real? Un padre "tanpeor”, pero apresable... aunque incumpla la función de sostener la ley con el deseo, y que ante el interrogante “¿es tan peor?, ¿quiere gozar(me)?” tiene una respuesta ineludible: ¡SÍ!

Con su sacrificio y el de su hijo, Abraham encubre la falta de Dios padre. Tan alto es el precio a pagar por obtener un padre Dios que brinde amparo y/o consistencia.

Lacan, citando a Schlomo Ben Isaac de Troyes del siglo XI, recoge un diálogo de Abraham con Dios: “(...) cuando el ángel dice: 'No extiendas' Abraham dice: 'En efecto, no viene aquí por nada; le haré al menos una ligera herida para complacerte, Elohim'” (20/11/1963). Versión que da cuenta de esa tentación maligna de Abraham de complacer al goce de Dios para tornarlo consistente y asegurarse de su existencia.

Dice Derrida que puede hablarse tanto del sacrificio de Abraham como el de Isaac: “. .. y es éste el sacrificio de los dos, el dar-(la)-muerte-al-otro dándose (la)muerte, mortificándose para dar esta muerte en ofrenda sacrificial a Dios...” (1999, p. 71).

En suma, para Abraham y para Isaac, es preferible temer a Dios que amarlo. El temor y el sacrificio apaciguan la angustia y, a su vez, hacen existir a Dios en plena consistencia. Marca implacable en la subjetividad que apostará siempre al temor más que al amor, porque el temor sacrificial asegura un padre pleno.

c. Desde Isaac: Finalmente nos preguntamos por Isaac. ¿Qué encubre ofreciéndose en sacrificio a Abraham? La respuesta la damos a partir de la ultima y quinta secuencia. 


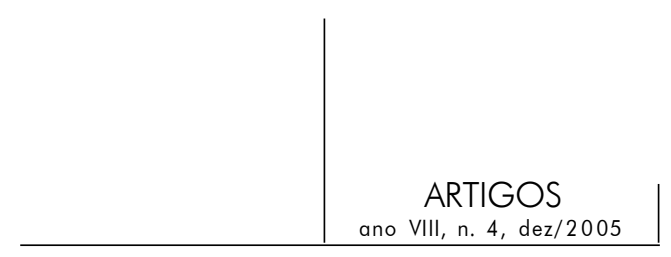

Quinta secuencia: el silencio de Isaac y su complicidad en el holocausto

¿Por qué no se revela Isaac a ser sacrificado? ¿por qué se somete tan dócilmente? No había recibido ningún mandato para dejarse sacrificar, ¿por qué, entonces, participaba y acompañaba tan mansamente a su padre? He aquí otro enigma.

Hay distintas versiones sobre la edad de Isaac en el momento del episodio del Monte Moriah. Una lo ubica como un niño, otra como un joven, otras como un hombre de 37 años, pero ¿por qué no se resiste al sacrificio? ¿Por qué guarda silencio - como su padre - sobre lo acontecido? ¿Por qué mantiene en secreto su ofrecimiento?

Kierkegaard (1991) dice: “Jamás se habló de esto en el mundo, ni nunca dijo Isaac nada a nadie sobre lo que había visto, y Abraham no sospechó que lo hubiera visto nadie" (p. 16).

También Isaac tiene que cubrir las faltas de Dios (quien manda a hacer lo prohibido en su ley) y las de Abraham. Son muchos los reproches que esconde el silencio de su sacrificio.

Cuando se afirma que El Sadday es el Dios de Abraham, de Isaac y de Jacob, se ubica la doble paternidad en la genealogía de Isaac: es hijo de la promesa de Dios a Abraham, es hijo de su Ley; y, a su vez es el hijo de Abraham y Sara, el de la bendición (Baraká) que asegurará la posteridad de su pueblo.

Pero conviene remitirnos a Génesis XXI:

10. Y ella (Sara) dijo a Abraham: "Echa afuera a esta sierva (Agar) y a su hijo, porque no heredará el hijo de esta sierva con mi hijo, con Isaac".

11. Y este dicho pareció muy gravoso a Abraham, con motivo de su hijo.

12. Y dijo Dios a Abraham: "No te parezca esto gravoso a causa del muchacho y a causa de tu sierva; en todo lo que te dijere Sara, oye su voz, porque en Isaac será llamada tu simiente.

Abraham expulsa a Agar y su hijo - ese al que no había dado nombre - al desierto, no vacila a pesar de las calamidades que probablemente sufrirían, incluso la de la muerte. Dios le manda obedecer a Sara. Una primigenia alianza de Abraham con Dios donde, también, se arriesga la vida de un hijo.

¿Qué padre es aquel que deja a su hijo a merced de las calamidades, incluida la muerte misma? ¿Qué Dios es ese que no detiene la iracundia de Abraham y permite la expulsión del primogénito?

Dios, finalmente, salva en el desierto al hijo de la esclava egipcia, le da el nombre de Ismael, y desde él también funda una nación. Pero está claro que no es el hijo de la promesa y que no recibió el mismo trato ni por parte de Abraham ni por parte de Dios. 


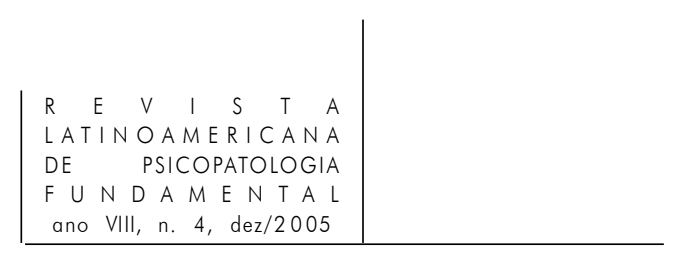

Si Dios y Abraham abandonaron a un hijo (Ismael), ¿por qué no harían lo mismo con Isaac? Había motivos para temer a Abraham y a su Dios, ya se habían ensañado con un hijo. Entonces, para sostenerlos como padres, debe ofrecerse para cubrir sus faltas y así obtener su amparo, única manera de quedar a salvo de su propia tentación parricida, estando muy cerca, en conjunción misma con ellos. Paradojas de la fascinación sacrificial: para tener garantías del Otro es preciso inmolársele en holocausto.

Dice Wiesel (1989):

... el padre y el hijo se alejaron juntos, ze laakod veze léaked, uno para atar y el otro para ser atado, ze lishkhot veze lishakhet, uno para sacrificar y el otro para ser sacrificado, compartiendo la misma obediencia para con el mismo Dios, respondiendo al mismo llamado. El sacrificio sería su ofrenda conjunta: antes, el padre y el hijo nunca habían estado tan cerca. (p. 74)

Isaac cubre con su silencio y complicidad en el holocausto, no sólo la falta de Dios a la que ya aludimos, sino las faltas de Abraham. Coartada para sostener la existencia de un Dios sin fallas y de un padre inmaculado. Coartada para amordazar el propio anhelo de goce parricida. No puede sino tender un manto que recubra la inconsistencia de aquellos padres aún a costa de la inmolación de su 612 vida. Esta es la razón de su secreto, secreto compartido con Abraham y con su Dios.

Isaac debió ocultar las faltas de Dios y de Abraham porque tenía muchos motivos para abonar su pasión parricida. Sin embargo, luego que Abraham sacrifica en holocausto al cordero primordial (Gén. XXII, p. 19), la economía del sacrificio de Isaac (etimológicamente: "el que ríe”) toma distancia con el goce de Dios y de Abraham.

Los caminos de padre e hijo se bifurcan, ya no bajan juntos del Moriah, Abraham lo hace solo.

A la postre Isaac recibirá la herencia simbólica de su Dios y de Abraham, y se despojará de la fascinación sacrificial (no toda), de ese sacrificio parricida en el que él participó complicentemente en la cima del Monte Moriah - allí donde su pueblo construirá el Templo - y de donde Isaac bajó con un resto del morueco (del urvater): el cuerno. Resto del padre vivo que recuerda el goce de Dios, pero también proclama su deseo, su perdón...

Isaac (el que ríe) es aquel que presenció el horror del goce de Dios y del goce de Abraham, pero - saldo de humor negro de su tragedia - logró reír finalmente. Concretó el parricidio simbólico: de lo que se trataba en el Monte Moriah era de la muerte del urvater y, por eso, el que ríe último ríe mejor.

Es cierto, con los años, también sufrirá el engaño (o la traición) de Jacob. Del mismo modo que Abraham, Isaac deberá portar ese resto de goce y padecer 
- por sus faltas - el anhelo parricida de su hijo. También Jacob sucumbirá a la tentación del sacrificio aunque, como en el caso de su abuelo y de su padre, esa tentación trocará en economía de goce (no-toda) desplazándose hacia el campo del deseo. De uno u otro modo las paradojas del padre lo han de confrontar con el deseo y el goce.

\section{El Goce del Otro y el Deseo del Otro en el sacrificio de Abraham y de Isaac. Consecuencias clínicas}

Retomemos los dos caminos antes trazados en torno al padre. Uno: el goce de Dios, ese que se pierde con el asesinato, el sacrificio del morueco (urvater). El otro: el deseo de Dios, aquel que queda luego de la alianza, del pacto con Dios.

Bifurcación que Lacan trabajará como goce y como deseo del Otro, y que señaláramos más arriba.

En el mito freudiano de Tótem y Tabú el protopadre (ur-vater: antes-delpadre) es un animal sin ley, anterior a la prohibición del incesto, a quien debe ofrecerse una satisfacción sin fin, dice Lacan. Pero, como señaláramos, el Tótem remite al animal y al Nombre como marcas. El Tótem ya no es sólo el animal, es también el padre muerto que inscribe una regulación que liga la ley con el deseo, aun cuando no dejará jamás de arrastrar el resto de lo real, del ur-vater. Por eso la cuestión a plantear es en el "antes" (ur), es en el origen primordial donde puede conjeturarse el goce puro del padre originario.

De ahí que, como remarcábamos más arriba, la bifurcación del goce del Otro y del deseo del Otro.

Satisfacer el goce del Otro supone no interrogarse por su deseo - ¿qué me quiere? - sino apostar a su goce y lo que le hace falta a ese goce para satisfacerse plenamente: ¿Por qué es tan peor, quiere gozar(me)?

Aquí Lacan recoge la tradición judía. Interroga no sólo por el goce de Dios sino por el deseo de Dios. La baraká (bendición) supone el favor de Dios como resultado de un pacto y de una alianza. La promesa paterna está del lado del deseo. Y ese morueco a matar es el retorno del padre primordial, el ancestro animal del Tótem, aquel cuyo resto se presentifica en la voz cavernosa del shofar. "El uso del shofar, que expresa a la vez el dolor y la esperanza dichosa imitando la voz del dios totémico, es otra prueba de que los impulsos en pugna estuvieron unidos alguna vez”. (Reik, 1928, p. 371). Aquello que el ángel de Yahvé indica como lo que finalmente ha de sacrificar Abraham es su ancestro en el sentido freudiano, es decir, el Dios vivo que tiene que morir para que reine su ley. No olvidemos que, para Freud y Lacan, el padre es muerto. 


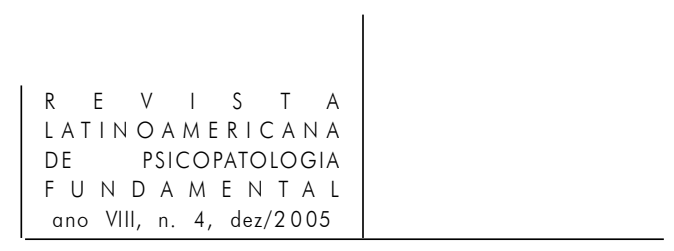

Se trata de operar - remarca Lacan en el Seminario inconcluso Los Nombres del Padre - "una línea divisoria entre el goce de Dios y lo que una tradición le designa como deseo, deseo de algo de lo cual se trata de provocar la caída, esto es, el orden biológico”.

En suma, debe producirse en Dios una pérdida de goce, una caída fundamental. ¿La caída de qué? la caída del origen biológico, del morueco y su voz, esto es, la caída del padre primordial.

Podemos mostrarlo trazando la línea divisoria que propone Lacan:

\begin{tabular}{|l|l|}
\hline \multicolumn{1}{|c|}{ Goce del otro } & \multicolumn{1}{c|}{ Deseo del otro } \\
\hline Morueco. Padre primordial & Tótem - Nombre del padre \\
\hline Ancestro biológico & La palabra nominante del padre \\
\hline Voz del superyó: objeto a & Palabra del padre \\
\hline Asesinato del urvater & Pacto y alianza con el padre \\
\hline Pedido imposible del padre & Bendición (Baraká) del padre como don \\
\hline Goce del padre & Contrato social: deseo y ley \\
\hline Temor al padre & Amor al padre \\
\hline Suplicio sacrificial & Sacrificio como pacto (don) \\
\hline
\end{tabular}

El superyó de un lado, la ley del deseo del otro. Un cuerpo que sostiene a una voz de un lado; el padre como Nombre del otro lado. Por una parte el ancestro biológico como fuente de goce; por otra el deseo del Otro que funda la ley. Pero hay una condición, la condición es la caída de la voz como objeto $a$, para que prime el deseo y la palabra del padre.

Hay, pues, un origen paradojal de la ley, de tal paradoja surge la bifurcación: goce del Otro y deseo del Otro. El significante de los Nombres del Padre intenta cernir el deseo y la ley, aunque siempre un remanente de goce escapa. El objeto $a$, como resto de goce, es incontorneable.

En este sentido, la divisoria que propone Lacan debe leerse desde una lógica de las paradojas y no desde una lógica binaria. La primera mantiene la contradicción y mantiene el resto, la binaria procura excluir el resto.

Recordemos que Lacan afirma en el Seminario X La angustia que el “... shofar, es la voz de Dios (...), de Yahvé...”, a lo que agrega “... la función del shofar (...) que en otros pasaje del texto bíblico llaman el mujido, el rugido de Dios” (1962/63. Sesión del 22/5/63). Es presencia del ancestro animal con la inaudible voz del superyó. Es eso lo que hay que perder para que el sacrificio tome la ruta del don por el lado del pacto y la promesa ligada al deseo del Otro. Pero; siempre ha de quedar un resto que, como suplicio sacrificial, involucra el ofrecimiento del cuerpo y la sangre. De allí que el sacrificio esté indisolublemente 


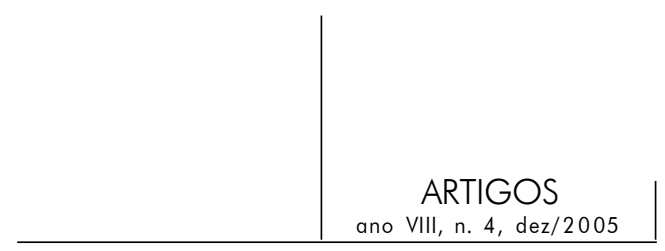

ligado a las paradojas de los Nombres del Padre, es decir, refiere a las faces del goce del padre (pére-versión), a esa tentación a volcarse (versar y girar) hacia lo peor del padre con tal de asegurarse de su existencia y consistencia.

En relación al deseo del Otro hay el pacto, hay el don: cara amable del sacrificio desde la cual el sujeto logra obtener una respuesta apaciguadora a la pregunta ¿qué quiere el Otro de mi?; mientras que, por otro lado, está la fascinación del sacrificio como fracaso inevitable de la estructura que no puede apaciguar la exigencia del goce del Otro, que oprime más allá de todo pacto y de toda reciprocidad.

\section{Referencias}

Derrida, Jacques (1999). Dar la muerte. Barcelona: Paidós, 2000.

Freud, Sigmund (1938). Moisés y la religión monoteísta. In: O. C. XXIII. Buenos Aires: Amorrortu, 1980.

KierkegaArd, Sören. Temor y temblor. 6. ed. Buenos Aires: Losada, 1991.

LaCAn, Jacques (1959-60). El Seminario. Libro VII. La ética del psicoanálisis. Buenos Aires: Paidós, 1988.

(1960). Subversión del sujeto y dialéctica del deseo en el inconsciente freudiano. In: Escritos II. 13. ed. Buenos Aires: Siglo XXI, 1985.

(1962/63). El Seminario. Libro X. La angustia. Inédito.

(20/11/1963). Seminario Los Nombres del Padre. Única lección. Inédito.

(1969-70). El Seminario. Libro XVII. El reverso del psicoanálisis. Barcelona:

Paidós, 1992. dito.

(1971). El Seminario. Libro XVIII. De un discurso que no fuese semblante. Iné-

(1/6/1972). Seminario $18^{a}$. El saber del psicoanalista - Charlas. In: Ste. Anne (1971/72). Inédito.

Reik, Theodor (1928). El ritual, estudio psicoanalítico de los ritos religiosos. Buenos Aires: Acme-Agalma, 1995.

Silvestre, Michel. Mañana el psicoanálisis. Buenos Aires: Manantial, 1988.

STEInER, George. Pasión intacta. Bogotá: Norma, 1997.

Wiesel, Elie. Mensajeros de Dios: retratos y leyendas bíblicos. Buenos Aires: Seminario Rabínico Latinoamericano, 1989. 


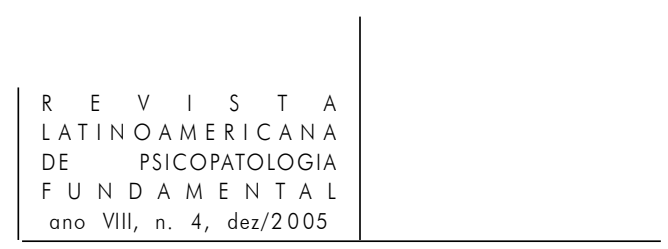

\section{Resumen}

O sacrifício na teoria psicanalítica, e desde o corpus freudo-lacaniano, é uma das conseqüencias dos paradoxos do pai.

Precisa-se acudir ao mito do sacrifício de Abraham para esclarecer as questões dos paradoxos dos Nomes-do-Pai e do fracasso da metáfora paterna, e assim destacar que não é possível reduzir os Nomes-do-Pai à dita metáfora. Sendo o sacrifício uma resposta à falta do Outro, e com o que se pretende sua captura, esse oferecimento pretende garantir que o Outro existe, seja pelas vias do gozo ou pelas do desejo.

Traçamos esse oferecimento de sacrifício no mito de Abraham e Issac e suas conseqüencias na clínica do desejo e do gozo.

Palavras-chave: Sacrifício, Nomes-do-Pai, objeto a, voz, gozo, desejo do Outro

Le sacrifice dans la théorie psychanalytique, et d'après le corps freudo-lacanien, est l'une des conséquences des paradoxes du père.

Il faut s'appuyer sur le mythe du sacrifice d'Abraham pour dénouer les questions des paradoxes des Noms du Père et de l'échec de la métaphore paternelle; et ainsi, souligner qu'il n'est pas possible de réduire les Noms du Père à cette métaphore. Le sacrifice étant une réponse au manque de l'Autre et à sa supposée capture, cette offrande tente de garantir que l'Autre existe déjà, soit par les voies de la jouissance, soit par celles du désir.

Nous apportons cette offrande sacrificielle dans le mythe d'Abraham et d'Isaac et ses conséquences dans la clinique du désir et de la jouissance.

Mots clés: Sacrifice, noms du père, objet a, voix, jouissance et désir de l’autre

Sacrifice in psychoanalytic theory, based on the Freudian-Lacanian field of study, is one of the consequences of the paradoxes of the father.

One must go back to the myth of the sacrifice of Abraham to clarify the question of the paradoxes of the Names of the Father and the failure of the Paternal Metaphor. We hold that the Names-of-the-Father cannot be reduced to the Paternal Metaphor. As the sacrifice is an answer to the lack of the Other, and with which one intends to capture it, this offer intends to guarantee that the other exists, either through jouissance or through desire.

We discuss this offer of sacrifice in the myth of Abraham and Isaac and its consequences in the clinic of desire and jouissance.

Key words: Sacrifice, Names-of-the-Father, object a, voice, jouissance, desire of the other

Versão inicial recebida em janeiro de 2005

Aprovado para publicação em setembro de 2005 